- Revista de Iniciação à Docência, v. 2, n. 2, 2017 Publicação: março, 2018 - ISSN 2525-4332

\title{
O ESTÁGIO SUPERVISIONADO EM GEOGRAFIA: O QUE NOS PROVOCA A EDUCAÇÃO INTERCULTURAL?
}

\author{
Gustavo Pereira de Souza ${ }^{1}$ \\ Gleice Kely Purificação Oliveira ${ }^{2}$ \\ Eduardo Oliveira Miranda ${ }^{3}$
}

RESUMO: O artigo abarca o processo formativo dos graduandos em Licenciatura em Geografia da Universidade Federal da Bahia, com destaque para o componente curricular Estágio Supervisionado em Geografia II. Neste cenário, apresentamos as contribuições da Educação Intercultural (SANTIAGO, AKKARI, MARQUES, 2013) associadas aos postulados teóricos do professor Boaventura de Souza Santos (2002). A metodologia da pesquisa pautou-se pela narrativa autobiográfica para a qual a nossa história de vida (JOSSO, 2005) deve ser considerada no âmbito da formação da identidade profissional, sobretudo, a partir do estágio docente (PIMENTA; LIMA, 2008, p. 100). Para tal, evidenciamos que a Educação Intercultural nos permite trazer para a roda do diálogo questões que estão instauradas no "chão da escola" e que repercutem no espaço geográfico, mas que por questões da razão indolente (SANTOS, 2002) não são problematizadas nos cursos de formação de educadores em Geografia.

Palavras-Chave: Educação Intercultural; Estágio Supervisionado; Identidade Docente; Narrativa Autobiográfica.

\section{Narrativas introdutórias}

Durante o nosso processo formativo docente somos convidados a todo tempo para adquirir competências e habilidades que nos proporcionem oportunizar um ensino-aprendizagem com foco no desenvolvimento intelectual dos discentes que compõem as salas de aulas da educação básica. Até aqui não nos opomos em estabelecer estes acordos, já que a nossa profissionalização requer bases teóricas que nos permitam fomentar o interesse dos educandos pelo conhecimento.

Contudo, percebemos uma lacuna no que tange ao trato com as questões subjetivas dos professores em formação inicial. Não queremos com isso disputar a centralidade da Educação e, muito menos, hierarquizar a dicotomia educando-

\footnotetext{
Licenciando em Geografia pela Universidade Federal da Bahia - UFBA. Email: gustavo_arembepe@hotmail.com

2 Licencianda em Geografia pela Universidade Federal da Bahia - UFBA. Email: gleicekelypurificacao@bol.com.br

${ }^{3}$ Licenciado em Geografia pela Universidade Estadual de Feira de Santana - UEFS. Mestre em Desenho, Cultura e Interatividade - UEFS. Especialista em Ensino de Geografia - UCAM. Doutorando em Educação - FACED/UFBA. Professor da FACED/UFBA. Email: eduardomiranda48@gmail.com
} 
- Revista de Iniciação à Docência, v. 2, n. 2, 2017 Publicação: março, 2018 - ISSN 2525-4332

educador. A nossa proposta procura despertar para o não desperdício das experiências (SANTOS, 2002) formativas dos graduandos das mais variadas licenciaturas.

Ao desperdiçar essas narrativas alicerçamos a descrença da potencialidade das experiências na efetivação de rupturas pedagógicas. Com isso, deixamos de fora as travessias, as reflexões sobre a prática educativa, a possibilidade de exprimir a existencialidade humana no trato com a Educação, como elucida Josso (2007):

A história de vida é, assim, uma mediação de conhecimento de si em
sua existencialidade, que oferece à reflexão de seu autor
oportunidades e tomada de consciência sobre diferentes registros
de expressão e de representações de si, assim como sobre as
dinâmicas que orientam sua formação (p. 419).

Sendo assim, evocamos neste artigo as nossas memórias articuladas durante os períodos da graduação e acrescidas às itinerâncias estabelecidas no componente curricular Estágio Supervisionado em Geografia Il, com caráter obrigatório para o curso de Licenciatura em Geografia da Universidade Federal da Bahia - UFBA.

O referido componente curricular apresentou duas etapas muito bem demarcadas, com o primeiro momento composto pelo embasamento teórico aplicado às conjunturas sociais, políticas, educacionais e culturais, com destaque para o estudo das seguintes produções literárias: i) "Para uma sociologia das ausências e uma sociologia das emergências", do pesquisador Boaventura de Souza Santos (2002); ii) "Educação Intercultural: desafios e possibilidades", de autoria de Santiago, Akkari e Marques (2013).

O segundo momento intensificou as nossas corporeidades no Colégio Estadual Mario Costa Neto (Figura 1) situado na Rua Engenheiro Jaime Zaverucha, s/n, Bairro da Federação, no município de Salvador-BA, lócus responsável por oportunizar a efetivação da nossa práxis pedagógica. 
- Revista de Iniciação à Docência, v. 2, n. 2, 2017 Publicação: março, 2018 - ISSN 2525-4332

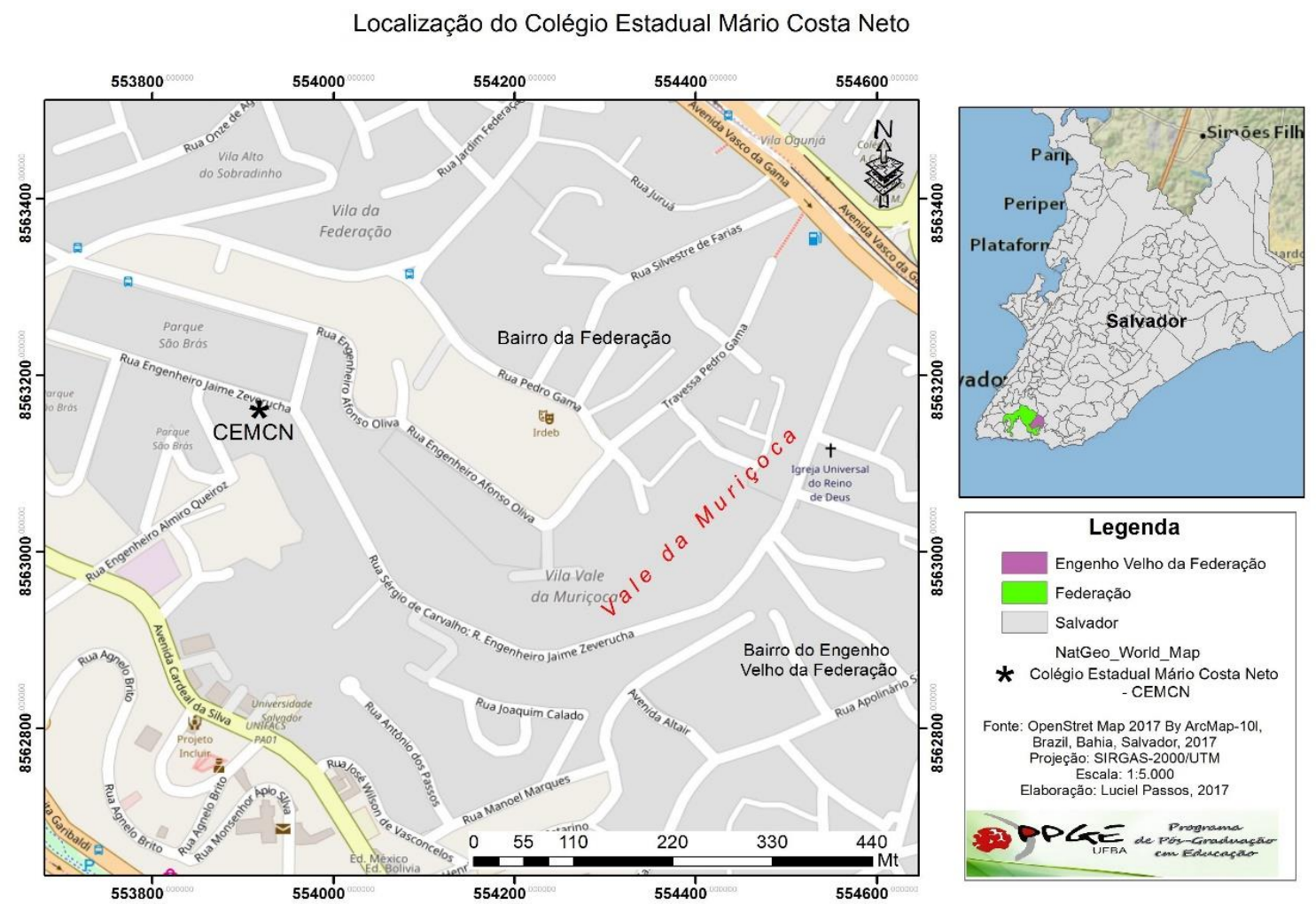

Figura 1. Lócus da práxis do Estágio Supervisionado em Geografia II - UFBA.

O terceiro e último momento do componente curricular culminou na tessitura do relatório que descreve e analisa a experiência formativa, cuja proposta deveria abarcar os entrecruzamentos das bases teóricas, as experiências desenvolvidas no lócus de estágio associadas com a construção da nossa identidade docente. Todo esse movimento nos conduziu a perceber a necessidade de acessar continuamente as nossas lembranças, refletir acercas das nossas práticas, entre outras questões que nos mobilizaram a repensar uma série de certezas. Portanto, a construção do nosso relatório pautou-se pelo uso da metodologia das narrativas autobiográficas, a qual também encontra neste artigo a sua relevância no conceber e projetar as presentes linhas textuais, pois assim como Miranda e Silva (2012, p. 2-3), acreditamos que:

O ato de evocar lembranças do passado mais recente ou não é reptador 4 já que as recordações evidenciam as nossas subjetividades. Isso do ponto de vista de um trabalho que aborda as narrativas autobiográficas, no qual as memórias revelam a nossa forma de agir, sentir, visualizar e perceber o mundo, nossa ação profissional e pessoal.

\footnotetext{
${ }^{4}$ A palavra "reptador" é pouco utilizada na escrita e na fala, mas a sua aplicabilidade se refere a uma situação desafiadora. Portanto, reptador é o mesmo que desafio.
} 
- Revista de Iniciação à Docência, v. 2, n. 2, 2017 Publicação: março, 2018 - ISSN 2525-4332

Nesse viés, após as movimentações metodológicas, apresentamos o objetivo central do artigo: analisar de que forma a perspectiva intercultural, articulada no Estágio Supervisionado em Geografia II, contribui para a formação docente dos graduandos do curso de Geografia da UFBA. Para tal, dividimos o artigo em duas sessões: i) Identidade docente: para pensar as ausências e as emergências; ii) Encruzilhadas: Educação intercultural e os postulados de Boaventura.

\section{Identidade docente: para pensar as ausências e as emergências}

$\mathrm{Na}$ contextualização das nossas ações pedagógicas discutidas durante o Estágio Supervisionado em Geografia II - UFBA, estabelecemos que o referido componente tem a prerrogativa de explorar e despertar nos estudantes o potencial de educador e pesquisador através da experiência adquirida com a prática de estágio e também com o exercício da profissão, como salienta Pimenta e Lima (2008, p. 100):

Como componente curricular, o estágio pode não ser uma completa preparação para o magistério, mas é possível, nesse espaço, professores, alunos e comunidade escolar e universidade trabalharem questões básicas de alicerce, a saber: o sentido da profissão, o que é ser professor na sociedade em que vivemos, como ser professor, a escola concreta, a realidade dos alunos nas escolas de ensino fundamental e médio, realidade dos professores nessas escolas, entre outras (PIMENTA; LIMA, 2008, p. 100).

Em nosso caso, especificamente, o componente curricular conseguiu traçar o encontro de graduandos em Geografia com experiência docente, assim como sujeitos que ainda não tiveram a oportunidade de assumir a regência de uma sala de aula. Com isso, verificamos que os diálogos e as trocas de experiências relatadas sobre o cotidiano profissional enriqueceram os debates fomentados em sala, permitindo que, mesmo aqueles que ainda não tinham assumido uma turma enquanto educadores ativos pudessem correlacionar com a realidade social a qual estavam inseridos, permitindo assim, uma troca de conhecimento mútua entre os estudantes.

Antes de partir para a observação em sala de aula da educação básica, construímos coletivamente um arcabouço teórico-conceitual por meio de leituras e discussões de diversos autores da área de Educação e da Geografia. Assim, as discussões realizadas em sala contribuíram de maneira significativa para que os estudantes envolvidos pudessem compreender a importância do desenvolvimento da pesquisa durante o processo de estágio. Outro fator importante que não podemos deixar de expor, e que se deve levar em consideração tem referência à construção da identidade profissional, esta que, por muitas vezes, pôde se refazer ou se auto afirmar a partir de cada nova experiência vivida, discutida e ampliada em sala. 
- Revista de Iniciação à Docência, v. 2, n. 2, 2017 Publicação: março, 2018 - ISSN 2525-4332

Dessa forma, essa atividade justifica-se como ação importante no desenvolvimento do processo de formação docente, tal qual nos propomos quando escolhemos o curso de Licenciatura em Geografia como formação profissional, pois é a partir dessas experiências que vamos construindo aos poucos a nossa identidade profissional, como destaca Buriolla (2001):

O estágio é o lócus onde a identidade profissional é gerada, construída e referida; volta-se para o desenvolvimento de uma ação vivenciada, reflexiva e crítica e, por isso, deve ser planejado gradativa e sistematicamente com essa finalidade (p. 13).

Então, no que concerne ao planejamento do estágio, podemos destacar do aprendizado em Estágio Supervisionado em Geografia II, as proposições postuladas pelo pesquisador Boaventura de Souza Santos (2002), com ênfase na razão indolente, razão metonímica, razão proléptica, juntamente com as cinco monoculturas que reproduzem as ausências na racionalidade ocidental. A partir das contribuições desse teórico, nos apropriamos de ideias para refletir sobre a escola e intensificar os nossos olhares para as seguintes provocações: epistemologias do sul, sociologia do direito, teoria pós-colonial, democracia, interculturalidade, globalização, movimentos sociais, direitos humanos.

O referido autor tensiona a tradicional razão ocidental, a qual denomina Razão Indolente que "subjaz, nas suas várias formas, ao conhecimento hegemônico, tanto filosófico como científico, produzido no Ocidente nos últimos duzentos anos" (SANTOS, 2002, p. 9) e propõe a Razão Cosmopolita, a qual "consiste em mostrar que qualquer totalidade é feita de heterogeneidade e que as partes que a compõem têm uma vida própria fora dela" (p. 246). Segundo o autor, a ciência social, tal como a conhecemos hoje em dia, não considera a enorme diversidade de experiências, pelo contrário, desqualifica muitas experiências alternativas. O objetivo da fundação desta nova racionalidade seria trazer para a cena social experiências desvalorizadas, invisibilizadas e desperdiçadas. Para tanto, três procedimentos são fundamentais: a sociologia das ausências, a sociologia das emergências e o trabalho de tradução.

Neste trabalho de valorização e resgate das experiências alternativas é necessário termos em mente que a compreensão do mundo está muito além do entendimento ocidental sobre ele, da noção de temporalidade linear e da sobrevalorização do futuro em detrimento do presente. A racionalidade cosmopolita deve então expandir o presente e contrair o futuro através de uma sociologia das ausências e uma sociologia das emergências, respectivamente. Além disso, não se pode criar uma teoria geral para dar conta das diversas experiências e sim deve ser realizado um trabalho de tradução entre essas diferentes práticas e saberes.

"O objetivo da sociologia das ausências é transformar objetos impossíveis em possíveis e com base neles transformar as ausências em presenças" (SANTOS, 2002, p. 246, grifo nosso), ou seja, a sociologia das ausências é pensada então como uma 
- Revista de Iniciação à Docência, v. 2, n. 2, 2017 Publicação: março, 2018 - ISSN 2525-4332

forma de transgressão da lógica de exclusão. Em seguida, o pesquisador destaca que a sociologia das emergências, na substituição do futuro demarcado pelo poder hegemônico, trabalha "por um futuro de possibilidades plurais e concretas, simultaneamente utópicas e realistas que vão se construindo no presente através das atividades de cuidado" (p. 246).

Tanto a sociologia das ausências, como a sociologia das emergências têm como fundamento uma postura de inconformismo. Quanto mais experiências houver e mais diversas forem, maior será a expansão do presente e contração do futuro. Para isso "a sociologia das emergências consiste em substituir o vazio do futuro [...] por um futuro de possibilidades plurais e concretas, simultaneamente utópicas e realistas, que se vão construindo no presente através das atividades de cuidado" (SANTOS, 2002, p. 254). É aproveitar o máximo do outro. Se relacionar. Expandir. Expansão das experiências sociais já disponíveis e das possíveis.

\section{Encruzilhadas: Educação intercultural e os postulados de Boaventura de Sousa Santos}

Nesse cenário e ainda com a perspectiva de planejar o estágio como pesquisa e formação, realizamos a discussão do livro Educação Intercultural: desafios e possibilidades da autoria de Santiago, Akkari e Marques (2013). Nesta obra, os autores "salientam que assumir a perspectiva intercultural impõe problematizar as ênfases e omissões curriculares com o objetivo de contribuir para a formação de gerações que aprendam a valorizar a diversidade cultural" (SILVA, 2015, p. 125). É justamente nesse ponto que encontramos a encruzilhada entre as omissões curriculares que encontramos e as propostas de Boaventura (2002), posto que as omissões fazem parte das estratégias da Razão Indolente para configurar a educação por um viés monocultural. Porém, a nosso ver, a formação docente precisa se ater às interculturalidades existentes e trazê-las para fecundar os planos de curso da ciência geográfica.

"A construção de uma educação intercultural implica, em nosso entender, na adoção do princípio da educação como direito de todos, com oportunidade de participação e aprendizagem e com garantia de acesso e permanência" (SANTIAGO, AKKARI, MARQUES, 2013, p. 45), o que configura a retórica de que a educação é um direito de todos. Todos têm que ser incluídos no sistema de ensino. Dessa maneira, a escola deveria levar em consideração as culturas que sempre, e ainda são desconsideradas nesse processo. Elas precisam se identificar, ser inseridas no processo de ensino-aprendizagem e permanecer nele. Para isso precisamos de políticas públicas que forneçam suporte para que ela exista e cumpra seu papel, de assegurar a permanência dos alunos até a sua formação. 
- Revista de Iniciação à Docência, v. 2, n. 2, 2017 Publicação: março, 2018 - ISSN 2525-4332

Dessa maneira, pensar em uma perspectiva intercultural implica em pensar em desconstruções: desconstrução dos modelos considerados padrões existentes e revisão de posturas e práticas homogeneizadoras, que desconsideram as subjetividades envolvidas. É ouvir os alunos; um processo que às vezes é lento e demorado. E muitas vezes, o sistema tão engessado, acaba levando alguns professores a atropelar esse processo e nem o realizando.

A troca de experiências vale muito a pena, visto que ambos, alunos e professores, crescem juntos compartilhando saberes. Na Geografia isso se torna ainda mais interessante. É possível criar inúmeras possibilidades em diversos assuntos que trabalhem com essas trocas entre professores e estudantes. $O$ aluno com a sua vivência, com o seu mapa mental, conhecendo lugares que o professor nunca foi e nem vivenciou, ao contrário, da mesma maneira, o que repercute na "adoção de uma perspectiva intercultural pode repercutir no cotidiano das instituições educacionais, favorecendo o diálogo entre as diferenças e problematizando discursos que essencializam as identidades" (SANTIAGO; AKKARI; MARQUES, 2013, p. 24).

Para tanto, os autores alertam "para não se reduzir a educação intercultural a algumas atividades realizadas em momentos específicos ou por determinadas áreas curriculares nem focalizar a atenção em determinados grupos sociais" (idem, p. 186). E como temos escolas tão plurais, todos têm que ser representados dentro desse ambiente. Por conseguinte, o dia da Consciência Negra, o dia do Índio, deveria ser tema de pautas durante o ano inteiro, não sujeitas apenas a uma semana do mês de abril e novembro. Em muitos casos as escolas acham que desenvolvem a educação intercultural ao "festejar" as referidas datas, fato que consideramos um equívoco. A educação intercultural vai muito além disso, ela requer representatividade, integração, inclusão e visibilidade todos os dias do ano, tanto na sala de aula quanto fora dos muros da escola. Os alunos acabam por se sentirem incluídos e participantes da escola. Ainda na perspectiva da interculturalidade:

A escola pode (...) tornar-se um espaço de ressignificação de símbolos culturais historicamente estereotipados, favorecendo a desconstrução de critérios para a "normalidade" que servem para classificar e hierarquizar as diferentes práticas e identidades (SANTIAGO; AKKARI; MARQUES, 2013, p. 189).

A escola precisa romper com esses padrões e ressignificar o lugar de sofrimento do diferente, com agressões legitimadas. Fugir do mesmo método para todas as escolas. Sabemos que é e será um exercício muito difícil abraçar a todos os alunos da sala. Mas é uma tarefa de conquista, de olhar o outro, de sensibilidade para entender, de conversar com os alunos e de trocar experiências.

Outro acerto do componente Estágio Supervisionado em Geografia II, se deu ao abordar o fator histórico da população negra no Brasil e, como esta cultura foi e 
ainda é alvo de toda a influência da razão indolente no nosso cotidiano. A luta desta etnia permitiu a conquista de muitos direitos, mas ainda falta muito a se percorrer para a busca de igualdade e a melhoria de vida e autoestima. Precisamos africanizar ${ }^{5}$ (LUZ, 2013) muitos espaços de construção do conhecimento para poder dar acesso ao que é de direito a todo cidadão brasileiro.

"O grande desafio do processo educacional é reconhecer os diferentes contextos de nossos estudantes" (SANTIAGO; AKKARI; MARQUES, 2013, p. 43). Isso é extremamente importante no sentido que a escola não se preparou e ainda não se encontra preparada para esse enfrentamento com a diferença dos alunos. Em problematizar esse tema. $\mathrm{E}$ dessa maneira vai usando apenas um método de ensino que, por muitas vezes, não leva em consideração a diferença de cada escola e de cada aluno, que tem ali sua própria essência. Dessa maneira, "o processo de formação docente é crucial para a articulação de um trabalho pedagógico voltado para o reconhecimento das diferenças enquanto oportunidade e enriquecimento no processo de ensino-aprendizagem" (SANTIAGO; AKKARI; MARQUES, 2013, p. 45). Precisamos sair da zona de conforto e devemos nos provocar, caso não haja quem faça isso, construir novos formatos de ensino, que fujam dos padrões tradicionais, enxergando o aluno não como único, mas como vários e diversos.

Durante toda o percurso do Estágio Supervisionado em Geografia II fomos convidados a falar de nós mesmos, relacionar os textos com as nossas realidades, com nossa sexualidade, traço étnico, questões raciais, convicções políticas, debates no âmbito do gênero e da diversidade. Notamos que tal prática foi pouco comum durante toda a nossa trajetória escolar e acadêmica. Dessa maneira, aprendemos a importância de nos conhecer e de conhecer o outro, repensando nossas posturas como pessoa, profissionais, ser humano, filhos e filhas, cidadã e cidadão, netos e netas, sobrinha e sobrinho. Ensinou-nos a repensar nossa vida, nossos gostos, nosso caráter, nossos preconceitos e conceitos, ao invés de apenas nos preocupar com os autores clássicos da Geografia, por exemplo.

Aprendemos a importância das aulas participativas, com a construção pautada nas nossas experiências de vida. Aprendemos também a importância de aulas fora dos moldes tradicionais e cartesianos e que isso é muito enriquecedor para o conhecimento. Outra situação muito relevante sobre essa experiência foram os conteúdos abordados, além de tudo aquilo que fora proposto inicialmente pela ementa da disciplina, também abordamos temáticas como diversidade e gênero, Razão das Emergências, africanizar a universidade, e todas as reflexões sobre o que não é considerado "padrão" pela sociedade. Todas essas ponderações estão

\footnotetext{
${ }^{5}$ LUZ, Narcimária Correia do Patrocínio. É preciso africanizar a universidade. In: MENEZES, J. M. F.; SANTANA, E. C.; AQUINO, M. S. Educação, região e territórios - formas de inclusão e exclusão. 1. ed. Salvador: Edufba, 2013. v. 1, p. 173-199.
} 
- Revista de Iniciação à Docência, v. 2, n. 2, 2017 Publicação: março, 2018 - ISSN 2525-4332

entranhadas em nossas identidades e serão levadas conosco em nossas ações e forma de vida durante todos os nossos dias de existência.

\section{Narrativas (in)conclusas}

Percorrer o lastro das nossas experiências articuladas durante o Estágio Supervisionado em Geografia II nos fez intensificar o processo de reflexão acerca das nossas ações, escolhas, posturas, ou seja, sobre como encaramos as vivências que perpassam pelas nossas corporeidades.

Traçar esse lastro fecundo de problemas propiciou realimentar a nossa escolha pela profissão docente, assim como, reafirmar as inúmeras barreiras e empecilhos ideológicos que levam a sociedade brasileira a desprestigiar o campo educacional e naturalizar a inferioridade do ser docente. Porém, da mesma forma que visualizamos os atalhos pejorativos, estamos nos permitindo compor um mosaico compreensivo para uma Educação Libertadora, Democrática e Justa.

Para tal, evidenciamos que a Educação Intercultural nos permite trazer para a roda do diálogo questões que estão instauradas no chão da escola e que se repercutem no espaço geográfico, mas que por questões da razão indolente não são problematizadas nos cursos de formação de educadores em Geografia.

As experiências no estágio aguçaram o nosso trato sobre as questões da nossa própria formação. Percebemos que discutir temáticas relativas à interculturalidade requer uma espécie de auto percepção acerca da nossa própria sexualidade, das nossas convicções políticas, por embates raciais e étnicos, do que compreendemos por gênero e até que ponto somos ou não preteridos pelo padrão. Todas estas subjetividades precisam ser bem trabalhadas na formação inicial dos futuros educadores, visto que a sala de aula exige da docência posicionamentos pautados nos direitos humanos.

\section{Referências}

BURIOLLA, M. A. F. O estágio supervisionado. 3 ed. São Paulo: Cortez, 2001.

JOSSO, M-C. A transformação de si a partir da narração de histórias de vida. Trad. de Maria do Carmo Monteiro Pagano. Educação - Porto Alegre/RS, ano XXX, n. 3 (63), p. 413-438, set./dez. 2007. Disponível em: <http://revistaseletronicas.pucrs.br/ojs/index.php/faced/article/view/2741/2088>. Acesso em: 21 jun 2017.

LUZ, N. C. do P. É preciso africanizar a universidade. In: MENEZES, J. M. F.; SANTANA, E. C.; AQUINO, M. S. Educação, região e territórios - formas de inclusão e exclusão. 1. ed. Salvador: Edufba, 2013. v. 1, p. 173-199. 
- Revista de Iniciação à Docência, v. 2, n. 2, 2017 Publicação: março, 2018 - ISSN 2525-4332

MIRANDA, E. O.; SILVA, H. M. S. Animai-vos, povo bahiense, que está por chegar o tempo que seremos todos iguais: relações étnico-raciais no espaço escolar. Cadernos Imbondeiro, v. 2, p. 1, 2012. Disponível em: < http://periodicos.ufpb.br/index.php/ci/article/view/14124/8749 >. Acesso em: 12 maio 2017.

PIMENTA, S. G.; LIMA, M. do S. L. Estágio e docência. $3^{\text {a } ~ e d . ~ S a ̃ o ~ P a u l o: ~ C o r t e z, ~} 2008$.

SANTIAGO, M. C. et al. Educação intercultural: desafios e possibilidades. Editora Vozes Limitada, 2013.

SANTOS, B. de S. Para uma sociologia das ausências e uma sociologia das emergências. Revista Crítica de Ciências Sociais, n. 63, p. 237-280, 2002. Disponível em: < https://rccs.revues.org/1285 >. Acesso em: 23 jul 2017.

SILVA, J. Educação intercultural: explorando a questão da identidade e da interculturalidade. Revista Agenda Social, v. 9, n. 2, p. 120-131, 2015. Disponível em: < http://www.revistaagendasocial.com.br/index.php/agendasocial/article/view/246/14 0 >. Acesso em: 19 jun 2017. 